\title{
Development of simple-to-apply biogas kinetic models for the co-digestion of food waste and maize husk
}

\author{
H.I. Owamah ${ }^{\mathrm{a}, *}$, O.C. Izinyon ${ }^{\mathrm{b}, 1}$ \\ ${ }^{a}$ Department of Civil Engineering, College of Science and Engineering, Landmark University, P.M.B. 1001, Omu-Aran, Kwara State, Nigeria \\ ${ }^{\mathrm{b}}$ Department of Civil Engineering, Faculty of Engineering, University of Benin, Benin, Edo State, Nigeria
}

\section{H I G H L I G H T S}

- Many existing biogas kinetic models are complex and substrate specific.

- BIK and MBPPSA models were hence developed in this study.

- BIK model was used for estimation of first order reaction rate constant $(k)$.

- MBPPSA model was used for prediction of maximum biogas production potential $(A)$ and digesters' stability.

- Developed MBPPSA and BIK models would be useful for feasibility studies and plant design.

\section{A R T I C L E I N F O}

\section{Article history:}

Received 2 April 2015

Received in revised form 25 June 2015

Accepted 28 June 2015

Available online 8 July 2015

\section{Keywords:}

Biogas

Inoculum

Model development

Stability assessment

\begin{abstract}
A B S T R A C T
Biogas kinetic models are often used to characterize substrate degradation and prediction of biogas production potential. Most of these existing models are however difficult to apply to substrates they were not developed for since their applications are usually substrate specific. Biodegradability kinetic (BIK) model and maximum biogas production potential and stability assessment (MBPPSA) model were therefore developed in this study for better understanding of the anaerobic co-digestion of food waste and maize husk for biogas production. Biodegradability constant $(k)$ was estimated as $0.11 \mathrm{~d}^{-1}$ using the BIK model. The results of maximum biogas production potential $(A)$ obtained using the MBPPSA model were found to be in good correspondence, both in value and trend with the results obtained using the popular but complex modified Gompertz model for digesters B-1, B-2, B-3, B-4, and B-5. The $\left(I_{\mathrm{f}}\right)$ value of MBPPSA model also showed that digesters B-3, B-4, and B-5 were stable, while B-1 and B-2 were inhibited/unstable. Similar stability observation was also obtained using the modified Gompertz model. The MBPPSA model can therefore be used as an alternative model for anaerobic digestion feasibility studies and plant design.
\end{abstract}

(c) 2015 Elsevier Ltd. All rights reserved.

\section{Introduction}

According to the Food and Agriculture Organization of the United Nations, over $30 \%$ of all food processed/manufactured for human consumption ultimately ends up as waste to give about $1.3 \times 10^{3}$ billion $\mathrm{kg}$ (Nathan and Pragasen, 2012). This large amount of food waste is evenly distributed between the developed and the developing countries. A huge amount of maize is produced annually in Nigeria and many other African countries, resulting in the generation of large quantities of maize husks $(\mathrm{MH})$ as wastes. Though at the moment, there is no easily accessible documented information on the actual amount of maize husk generated in Nigeria, the FMAWR

\footnotetext{
* Corresponding author. Tel.: +234 8035705814.

E-mail addresses: owamah.hilary@lmu.edu.ng, dahilla222@yahoo.com (H.I. Owamah), izinyon2006@yahoo.com (O.C. Izinyon).

1 Tel: +23435038239
}

(1998) has estimated that about 4.11 million tonnes of maize residues are generated annually in Nigeria alone. These maize residues comprise mainly straw, husks, skin and trimmings, and cobs. Maize husks are usually burnt in open places or used as fire starter for cooking purposes in rural African communities. These disposal methods are wasteful and impacts negatively on climate.

Globally, the high dependence on fossil energy fuels for industrial, commercial and domestic energy needs has resulted in climate change, many environmental destructions and related human health problems (Budiyono et al., 2010; Owamah, 2014). The challenge posed by global pollution and depletion of fossil fuels has motivated the search for development and utilization of renewable energy, among which is biogas (Gueguim et al., 2012; Owamah et al., 2014a). For proper enhancement of biogas production from anaerobic digestion, adequate quantity of active inoculum is necessary. Inoculum comprises complex community of microbes that are capable of accelerating anaerobic biochemical 
processes (Boulanger et al., 2012). The effect of inoculum to substrate $(I / S)$ ratio is therefore necessary for the determination of the efficiency of biogas production from anaerobic digestion (Boulanger et al., 2012). Addition of inoculum to substrate could help to overcome the inhibition of digesters (Moreno-Andrede and Buitron, 2003). Increase in $I / S$ ratio was reported to increase methane production from the anaerobic digestion of sun oil flower cakes (Raposo et al., 2009). Recently, Boulanger et al. (2012) reported that $I / S$ ratio 2 was the best for optimum production of biogas from the anaerobic digestion of municipal solid waste.

Several biogas kinetic models based on kinetics of growth of microorganisms and biogas yield have been developed for describing the degradation of substrates, substrate selection, digester sizing and stability assessment (Gerber and Span, 2008; Momoh et al., 2013). These kinetic models are relatively different from one another because of their varied objectives and levels of complexity (Gerber and Span, 2008). Also, because the growth rate of microorganisms is dependent on the nature of substrates, many of the existing models are obviously applicable to unique substrates or a limited number of substrates; it therefore becomes very difficult to apply some of these models to substrates they were not originally developed for, without experimental confirmation (Gerber and Span, 2008).

Furthermore, majority of the biogas kinetic models in literature were developed for low energy substrates such as wastewater and as such cannot be properly utilized for complex and high energy substrates (Linke, 2006; Momoh et al., 2013), like food waste and maize husk. The application of many of the existing models is also very difficult as the equations are usually complex and require special computing skill and software, not too convenient at the moment for existing and emerging renewable energy researchers in developing countries. Following this, simple-to-apply biodegradability kinetic (BIK) model and maximum biogas production potential and stability assessment (MBPPSA) model were developed in this study for better understanding of biogas production from food waste and maize husk. Results obtained were validated though a comparison with the results from the popular but complex modified Gompertz model.

\section{Method}

\subsection{Collection of materials}

Food waste used for this study was collected from the Waste bins of the Cafeteria at Landmark University, Omu-Aran, Kwara State. The collections were done on daily basis, within five working days of a week, from Monday 24th March to Friday 28th March, 2014. In accordance with the procedure in Owamah et al. (2014b), the food waste was collected at 12 noon and $7 \mathrm{pm}$ of each day, to coincide with students' time of peak consumption and waste generation. The purpose of collecting food waste over 5 -working days was to reduce nutritional variations in the food waste collected. The maize husks were obtained from Landmark University Farm, Omu-Aran, Kwara State. It was initially kept dry in a sack, in the Environmental Engineering Laboratory of Landmark University, prior to the commencement of the anaerobic digestion experiment. Similar approach was recently used by the Authors (Owamah and Izinyon, 2015).

\subsection{Substrates preparations}

\subsubsection{Food waste}

Following the procedures used in Zhang et al. (2006), El-Mashad and Zhang (2010) and Owamah and Izinyon (2015), bones and inorganic materials in the food waste were sorted out within $24 \mathrm{~h}$ of collection. This was followed by the crushing and homogenization of the food waste using a mini electric blender. The blended food waste was then kept in a freezer at approximately $4{ }^{\circ} \mathrm{C}$, before the commencement of the anaerobic digestion experiment in April 10, 2014.

\subsubsection{Maize husks}

Following the procedure in Zhu et al.(2014), Owamah and Izinyon (2015), the collected maize husks were ground to powdery form using a grinder. Ground maize husk was then kept in a container that was air tight until it was used for the experiment.

\subsection{Analysis of chemical parameters of the prepared food waste and maize husk substrates}

The prepared food waste and maize husk substrates, before they were mixed together for anaerobic digestion experiment were analyzed for their relevant chemical parameters. The total solids (TS) and volatile solids (VS) were measured in triplicate according to the Standard Methods for the Examination of Water and Wastewater (APHA, 2012) using a laboratory oven, model DHG-9053A manufactured by Controls, Italy. Following standard procedures in APHA (2012), the food waste and maize husk substrates were also analyzed for $\left(\mathrm{NH}_{4}^{+}-\mathrm{N}, \mathrm{TKN}, \mathrm{Cl}, \mathrm{P}, \mathrm{K}, \mathrm{S}, \mathrm{Na}, \mathrm{Ca}\right.$, $\mathrm{Mg}$ ) using a direct-reading photometer (Palintest Photometer, models 7100 and 7500) manufactured in England by ELE. Carbon contents of the substrates were measured using standard procedures in APHA (2012). The initial pH values of the food waste and maize husk substrates were measured using $\mathrm{pH}$ meter, model PHS-3C, manufactured by SEARCH TECH, United Kingdom. Weighing balance (model KERN 572) manufactured by KERN and SOHN, Germany, was used for measuring the mass of the substrates. Similar procedures were recently used by the Authors (Owamah and Izinyon, 2015).

\subsection{Anaerobic digestion experiment}

The batch anaerobic digestion experiment was carried out to determine the effect of inoculum to substrate $(I / S)$ ratio on biogas production at the established optimum combination of $75 \%$ food waste and 25\% maize husk (Owamah, 2015; Owamah and Izinyon, 2015). Effluent from an anaerobic digester treating similar substrate was used as inoculum for the digestion experiment. Five identical 101 digester reactors with 51 working volume each (B-1, B-2, B-3, B-4, and B-5) were used for the experiment. In line with Boulanger

Table 1

Feeding (influent) substrate characteristics.

\begin{tabular}{|c|c|c|c|c|c|}
\hline Parameters & Digester B-1 & Digester B-2 & Digester B-3 & Digester B-4 & Digester B-5 \\
\hline FW: $\mathrm{MH}(\%)(\mathrm{w} / \mathrm{w})$, based on total weight $(\mathrm{g})$ & $75: 25$ & $75: 25$ & $75: 25$ & $75: 25$ & $75: 25$ \\
\hline Total weight of sample $(\mathrm{g})$ & 30 & 30 & 30 & 30 & 30 \\
\hline Weight of FW (g) & 22.5 & 22.5 & 22.5 & 22.5 & 22.5 \\
\hline Weight of $\mathrm{MH}(\mathrm{g})$ & 7.5 & 7.5 & 7.5 & 7.5 & 7.5 \\
\hline VS $(g / L)$ & 3.5 & 3.5 & 3.5 & 3.5 & 3.5 \\
\hline $\mathrm{C} / \mathrm{N}$ ratio & 23.4 & 23.4 & 23.4 & 23.4 & 23.4 \\
\hline $\mathrm{pH}$ & 7.2 & 6.9 & 6.8 & 7.1 & 5.9 \\
\hline$I / S$ & 0.25 & 0.5 & 1 & 2 & 4 \\
\hline
\end{tabular}


et al. (2012), five (5) treatments with $I / S$ ratios $0.25,0.5,1,2$, and 4.0 were used for reactors B-1, B-2, B-3, B-4, and B-5 respectively. The FW: $\mathrm{MH}$ mixture percentage, $\mathrm{pH}$, weight, $\mathrm{VS}$ and $\mathrm{C} / \mathrm{N}$ ratio, and $\mathrm{I} / \mathrm{S}$ ratios of the feeding substrate were also determined and shown in Table1. Total and volatile solid contents of the inoculum, $\mathrm{pH}$, and $\mathrm{C} / \mathrm{N}$ ratio are $6.8 \pm 0.3,3.4 \pm 0.1,7.5$ and 6.6 respectively.

The reactors of the digesters were also run steadily at mesophilic temperature of $37 \pm 1^{\circ} \mathrm{C}$, through an inbuilt water bath of the anaerobic digester. The substrates were fed from an overhead influent tank into the reactors through inbuilt peristaltic pumps and flow meters in the computer controlled anaerobic digester. The flow was set to the maximum of 71 per day in order to fill the reactor of $5 \mathrm{l}$ working volume within the period of 18-20 h. The inflow of substrate was terminated after the working volume of the reactors were completely filled. A solid retention time of 44 days was used for the anaerobic digestion. The volume of biogas produced was measured daily at 12 noon, through water displacement method from the volumetric tank of the anaerobic digester. In line with Boe et al. (2010), the displaced water was initially acidified to $\mathrm{pH} 3$ using hydrochloric acid $(\mathrm{HCl})$ before the addition of sodium chloride $(\mathrm{NaCl})$, to reduce the dissolution of $\mathrm{CO}_{2}$ into water. The temperature and $\mathrm{pH}$ of the anaerobic digestion process was constantly measured online through inbuilt sensors of the digester. Anaerobic digestion in each reactor was terminated after 44 days, when either no measurable or significant biogas production was obtained. The experiments were run in duplicate and mean values of daily biogas production were recorded.

Two blank digesters containing only the inoculum and water were operated at same mesophilic temperature of $37 \pm 1{ }^{\circ} \mathrm{C}$ in order to obtain the background biogas generated from the inoculum. The average background biogas production of the inoculum was thereafter subtracted from biogas produced. Initial TS of feeding substrates was also maintained at $8 \%$, which is within the recommended range of $6-12 \%$ (Tchobanoglous et al. 1993). The methane content of biogas was analyzed twice in a week using a gas chromatograph (BUCK GC122, China) equipped with a Stabilwax-DA column $(0.3 \mathrm{~m} \times 0.32 \mathrm{~m} \times 0.5 \mu \mathrm{m})$ and FID. Nitrogen gas was used as carrier gas at a flow rate of $5.2 \mathrm{~mL} / \mathrm{min}$. The column and detector temperatures were set at $40^{\circ} \mathrm{C}$ and $200{ }^{\circ} \mathrm{C}$, respectively. A mesophilic semi-continuous anaerobic digestion experiment using $75 \% \mathrm{FW}$ and $25 \% \mathrm{MH}$ was also carried out for over 100 days in order to obtain different values of volatile solid reduction at different retention times, when digestion process was fairly at steady state. Similar experimental procedure was recently used by the Authors (Owamah and Izinyon, 2015).

\subsection{Fitting of experimental data using the modified Gompertz model}

The popular modified Gompertz equation given as Eq. (1) is used for estimating important kinetic parameters of anaerobic digestion process.

$A_{\mathrm{t}}=A \exp \left\{-\exp \left[\frac{R_{\mathrm{m}} \times e}{A}(\lambda-t)+1\right]\right\}$

Eq. (1) has been used by many authors for prediction of maximum biogas production potential, specific maximum biogas production and lag time (latency) (Li et al., 2014; Zhu et al., 2014, etc). Parameter A, is maximum biogas production potential (L/g VS), $R_{\mathrm{m}}$ is maximum specific biogas production (L/g VS/day) and $\lambda$ is latency (days), $t$ is time of biogas production (days), $A_{\mathrm{t}}$ is cumulative biogas production (L/g VS). The modified Gompertz model was carefully used to fit the experimental data of this study in order to determine some important kinetic parameters necessary for digester design and optimal operation of large scale anaerobic plants that would possibly treat food waste and maize husk substrates. The solutions to Eq. (1) were obtained using the optimization tools of the Solver Function in Microsoft Excel 2010 version.

\section{Development of kinetic models}

Given the challenges of complexity and uniqueness of existing biogas kinetic models for describing and predicting anaerobic digestion processes, the authors in this study developed two set of biogas kinetic models called; biodegradability kinetic (BIK) model and maximum biogas production potential and stability assessment (MBPPSA) model to assist in the better understanding of biogas production from food waste and maize husk.

\subsection{Development of biodegradability kinetic (BIK) model}

The first order reaction constant $(k)$, also known as biodegradability constant of a substrate is an important parameter for the prediction of the feasibility of using a substrate for large scale production of biogas. It also assists in the design of anaerobic digestion plants.

For a continuous system, without recirculation of solids, the mass balance equation can be written as:

$V_{\mathrm{R}} \frac{d c}{d t}=Q_{0} C_{0}-Q_{0} C+V_{\mathrm{R}} r_{\mathrm{C}}$

where $V_{\mathrm{R}}$ is the volume of reactor, $Q_{0}$ is flow rate, $C_{0}$ is influent volatile solids concentration, $C$ is effluent volatile solid concentration and $r_{\mathrm{c}}$ is the substrate removal rate.

but $V_{\mathrm{R}}=Q_{0} \times \theta$

where $\theta$ is the hydraulic retention time (days).

Substituting Eq. (3) into Eq. (2), gives;

$Q_{0} \theta \frac{d c}{d t}=Q_{0} C_{0}-Q_{0} C+Q_{0} \theta r_{C}$

Eq. (4) can also be written as;

$Q_{0} \theta \frac{d c}{d t}=Q_{0}\left(C_{0}-C\right)+Q_{0} \theta \cdot r_{\mathrm{C}}$

Dividing both sides of Eq. (5) by, $Q_{0} \theta$ gives;

$\frac{d c}{d t}=\frac{C_{0}-C}{\theta}+r_{C}$

Eq. (6) can also be written as;

$\frac{d c}{d t}=r_{\mathrm{C}}+\frac{C_{0}-C}{\theta}$

at steady state, $r_{\mathrm{C}}=-k \cdot C, r_{\mathrm{C}}=$ substrate utilization rate; $k=$ first order rate kinetic $\left(\mathrm{d}^{-1}\right)$ and $C=$ substrate concentration at steady state.

Also at steady state, $\frac{d c}{d t}=0$

Therefore, Eq. (7) transforms to Eq. (8)

$k \theta=\frac{C_{0}-C}{C}$

Multiplying both sides of Eq. (8) by $\frac{c}{C_{0}}$ gives;

$k \theta \frac{C}{C_{0}}=\frac{C_{0}-C}{C_{0}}$

From Eq. (9), $k \theta=\frac{C_{0}}{C}-\frac{c}{C}$; which can also be written as,

$k \theta=\frac{C_{0}}{C}-1$

$\therefore k \theta+1=\frac{C_{0}}{C}$
$\Rightarrow \frac{1}{k \theta+1}=\frac{C}{C_{0}}$ 


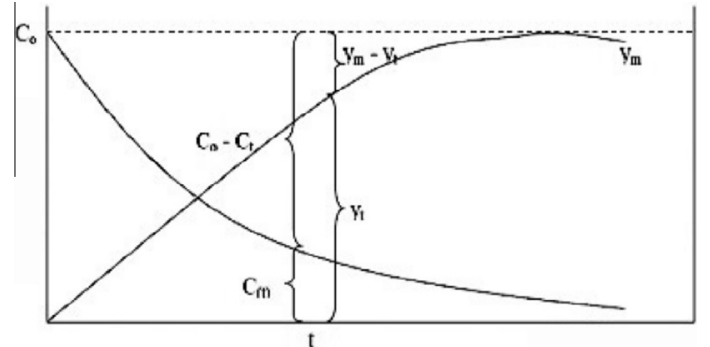

Fig. 1. Substrate degradation and biogas yield correlation.

Substituting Eq. (10) into Eq. (9), gives Eq. (11);

$\frac{k \theta}{k \theta+1}=\frac{C_{0}-C}{C_{0}}$

Assuming an ideal condition, that all substrates are digested to yield biogas, then the correlation between substrates degradation and biogas yield can be represented by Fig. 1 (Linke, 2006; Momoh et al., 2013; Igal et al., 2014).

From Fig. 1,

$\frac{C_{0}-C_{\mathrm{t}}}{C_{0}}=\frac{y_{\mathrm{t}}}{y_{\mathrm{m}}}$

and $\frac{C_{0}}{C_{\mathrm{t}}}=\frac{y_{\mathrm{m}}}{y_{\mathrm{m}}-y_{\mathrm{t}}}$

where $y_{\mathrm{t}}$ is biogas yield at time $(t)$ and $y_{\mathrm{m}}$ is maximum biogas yield, $C_{\mathrm{t}}=C$ and represents the effluent volatile concentration at time $(t)$, $C_{0}$ is influent volatile solid concentration.

Substituting Eq. (11) into Eq. (12), gives;

$\frac{k \theta}{k \theta+1}=\frac{y_{\mathrm{t}}}{y_{\mathrm{m}}}$

$y_{\mathrm{t}}$ and $y_{\mathrm{m}}$ are correlated with $\mathrm{VS}_{\mathrm{r}}$ and $\mathrm{VS}_{\mathrm{rm}}$ by Eq. (15), where $\mathrm{VS}_{\mathrm{r}}$ is volatile solid reduction at time $(t)$ and $\mathrm{VS}_{\mathrm{rm}}$ is maximum volatile solid reduction (Dai et al., 2013)

$\frac{y_{\mathrm{t}}}{y_{\mathrm{m}}}=\frac{\mathrm{VS}_{\mathrm{r}}}{\mathrm{VS}_{\mathrm{rm}}}$

Substituting Eq. (14) into Eq. (15), gives Eq. (16);

$\frac{\mathrm{VS}_{\mathrm{r}}}{\mathrm{VS}_{\mathrm{rm}}}=\frac{k \theta}{k \theta+1}$

Inverting Eq. (16), gives;

$\frac{k \theta+1}{k \theta}=\frac{\mathrm{VS}_{\mathrm{rm}}}{\mathrm{VS}_{\mathrm{r}}}$

In completely mixed anaerobic digester where no recycling occurs, the solid retention time (SRT) is the same as the hydraulic retention time $(\theta)$ (Ezekoye et al., 2011). Making $k \theta$ the subject of Eq. (16) and substituting $\theta$ with SRT, gives Eq. (17)

$\frac{\mathrm{VS}_{\mathrm{r}}}{\mathrm{VS}_{\mathrm{rm}}-\mathrm{VS}_{\mathrm{r}}}=k(\mathrm{SRT})$

Provided $\mathrm{VS}_{\mathrm{rm}}$ is known, $k$ can easily be determined as the slope of Eq. (17) by the plot of $\frac{V S_{r}}{V S_{r m}-V S_{r}}$ against SRT.

In line with Chen and Hashimoto (1978), and Dai et al. (2013), $\mathrm{VS}_{\mathrm{rm}}$ can be obtained as the intercept of the plot of $\frac{1}{\mathrm{SRT}}$ versus $\mathrm{VS}_{\mathrm{r}}$.
3.2. Development of maximum biogas production potential and stability assessment (MBPPSA) model

Linke (2006), and Momoh and Nwaogazie (2011) in their studies on anaerobic digestion, developed simple models for the determination of maximum biogas yield $\left(y_{\mathrm{m}}\right)$.

Following the procedure they adopted, based on mass balance; $V_{\mathrm{R}} \frac{d c}{d t}=Q_{0} \cdot C_{0}-Q_{0} \cdot C+V_{\mathrm{R}} r_{\mathrm{c}}$ where $V_{\mathrm{R}}$ is the volume of reactor, $Q_{0}$ is flow rate, $C_{0}$ is influent volatile solids concentration, $C$ is effluent volatile solid concentration and $r_{\mathrm{c}}$ is the substrate removal rate.

In batch systems, $Q_{0}=0$.

$\therefore V_{\mathrm{R}} \frac{d c}{d t}=V_{\mathrm{R}} r_{\mathrm{c}}$

$\frac{d c}{d t}=r_{\mathrm{c}}$

but $r_{\mathrm{c}}=-k C$

$\therefore \frac{d c}{d t}=-k C$

where $k$ is the first order kinetic constant (biodegradation constant). Integrating Eq. (20), gives;

$\ln \frac{C_{0}}{C_{\mathrm{t}}}=k t$

From Fig. 1 (Linke, 2006; Momoh and Nwaogazie, 2011; Igal et al., 2014), the relationships between substrate degradation and biogas yield, were explained using Eqs. (12) and (13); $\frac{C_{0}-C_{t}}{C_{0}}=\frac{y_{t}}{y_{m}}$ and $\frac{C_{0}}{C}=\frac{y_{\mathrm{m}}}{y_{\mathrm{m}}-y}$ respectively.

By substituting Eq. (12) into Eq. (21),

Momoh and Nwaogazie (2011) obtained

$y_{\mathrm{t}}=y_{\mathrm{m}}\left(1-e^{-\mathrm{kt}}\right)$

Linke (2006) also obtained

$\mathrm{HRT}=\frac{1}{k}\left(\frac{y}{y_{\mathrm{m}}-y}\right)$

While Eq. (22) was used by Momoh and Nwaogazie (2011) to determine the maximum biogas yield of substrates used, Linke (2006) used Eq. (23) to determine biodegradability constant $(k)$.

However, the Momoh and Nwaogazie (2011) model of Eq. (22) and the Linke (2006) model of Eq. (23) did not take the mixing ratio of substrates $(n)$, especially for co-digestion scenarios into consideration. The models therefore have limitations for predicting the maximum biogas production potential of substrates $(A)$. It also was not suitable for determining the stability/inhibition status of anaerobic digestion process. Furthermore, the modified Gompertz model have been extensively used in literature for determining the maximum biogas production potential of substrates, without an alternative simple model for verifying the results obtained from the model. Moreover, the modified Gompertz equation is complex and usually requires special skill and software for analyzing it. It also does not have the capacity to assess in simple terms the stability /inhibition status of anaerobic digestion processes.

In an approach to contributing to solving the above mentioned problems, the authors here, modified Eq. (22), by introducing some relevant variables as shown.

Let $y_{\mathrm{m}}$ in Eq. (22) be substituted by $A$ (Igal et al., 2014), to give;

$y_{\mathrm{t}}=A\left(1-e^{-\mathrm{kt}}\right)$

$A$ is the maximum biogas production potential (same as $A$ in modified Gompertz equation).In order to account for the mixing ratio of substrates, Eq. (24) was raised to power $n$, to give Eq. (25). 
$y_{\mathrm{t}}=A\left(1-e^{-\mathrm{kt}}\right)^{\mathrm{n}}$

where $n$ is the ratio of the major substrate to the minor substrate being digested (in co-digestion scenarios).

When the substrates are mixed in equal amount, $n=1$.

Replacing $y_{\mathrm{t}}$ by $A_{\mathrm{t}}$, for unification of letters, we have

$A_{\mathrm{t}}=A\left(1-e^{-\mathrm{kt}}\right)^{\mathrm{n}}$

Adding $\left(I_{\mathrm{f}}\right)$ to Eq. (26) to make the equation conform with general form of linear equations $(y=m x+c)$, gives

$A_{\mathrm{t}}=A\left(1-e^{-\mathrm{kt}}\right)^{\mathrm{n}}+I_{\mathrm{f}}$

where $\left(I_{\mathrm{f}}\right)$ is intercept of Eq. (27) and represents the inhibition/stabil ity/feasibility determination factor.

Once $k$ is known, using BIK model of Eq. (17) developed here or any another suitable method, $A$ can then be obtained as the slope of the plot of $A_{\mathrm{t}}$ against $\left(1-e^{-\mathrm{kt}}\right)^{\mathrm{n}}$. The intercept of the plot represents $\left(I_{\mathrm{f}}\right)$.

At represents cumulative biogas yield of experimental data. The unit of $A$ is $\mathrm{L} / \mathrm{g} \mathrm{Vs}, \mathrm{L} / \mathrm{kg} \mathrm{VS}, \mathrm{ml} / \mathrm{g} \mathrm{VS}$, and other lower and higher units of this form. Negative $\left(I_{\mathrm{f}}\right)$ indicates feasible or non-inhibited process, while positive $\left(I_{\mathrm{f}}\right)$ represents non-feasible (inhibited process). Furthermore, the higher the absolute value of the negative $\left(I_{\mathrm{f}}\right)$, the higher the feasibility of the process would become. In the same vein, the higher the positive value of $\left(I_{\mathrm{f}}\right)$, the more inhibited (non-feasible) the process becomes. However, the MBPPSA model is developed on the assumption that only one or two substrates are digested at a time. In a three substrate situation, it is expected that one substrate should be kept constant while the two other are varied in order to suit the MBPPSA model. However, further investigations on applicability of the model to the digestion of three or more substrates in one digester is recommended.

\section{Results and discussion}

\subsection{Effect of I/S ratio on digester performance}

It has been suggested in literature that the addition of inoculum to substrate could have a significant impact on biogas yield, thereby making the selection of appropriate $I / S$ ratio imperative for the sustainable operation of large scale anaerobic digestion plants (Raposo et al., 2009; Boulanger et al., 2012). The $I / S$ ratios in digesters B-1, B-2, B-3, B-4, and B-5 are $0.25,0.5,1,2$, and 4 . Digester B-3 with $I / S$ ratio of 1 had a significantly $(p<0.05)$ higher biogas yield than the other four digesters. Digester B-3 had the highest cumulative biogas yield of (28.92 L/g VS), while digesters B-1, B-2, B-4, and B-5, had cumulative biogas yield of 5.55, 6.97,19.7 and14.85 L/g VS respectively. From Fig. 2, the peak biogas

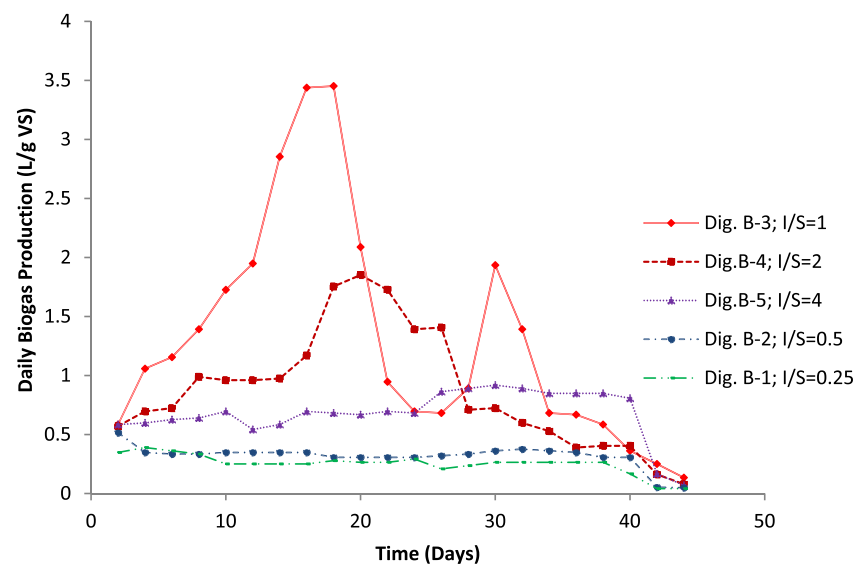

Fig. 2. Daily biogas production at the different $I / S$ ratios.

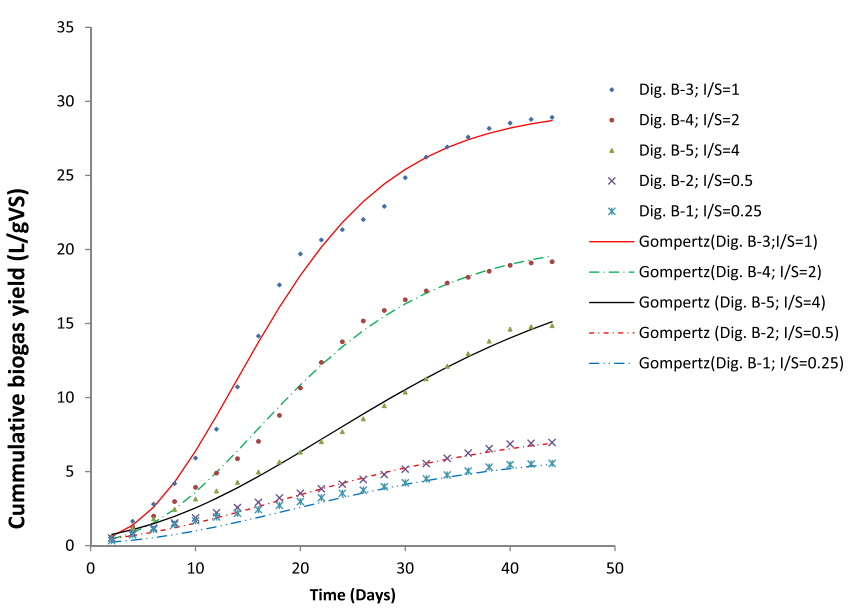

Fig. 3. Simulation of experimental data with modified Gompertz model at different $I / S$ ratios.

yield of digester B-3 is significantly higher than the peak yield of the other digesters. Details of the result on the effect of $I / S$ ratio on biogas production from the co-digestion of food waste and maize husk can be found in Owamah (2015).

\subsection{Simulation of experimental data using modified Gompertz model}

Experimental data obtained from digesters B-1, B-2, B-3, B-4, and B-5 were simulated using the modified Gompertz model, for the determination of relevant kinetic parameters necessary for evaluation of the performance of digesters and process. The simulation plot of biogas production from digesters; B-1, B-2, B-3, B-4, and $\mathrm{B}-5$ is shown in Fig. 3. The kinetic parameters obtained from the simulation of the experimental data with modified Gompertz model are shown in Table 2. Again, the modified Gompertz model shows that digester B-3 performed better than the other digesters as it had the least latency $(\lambda)$, and highest maximum biogas production potential $(A)$ and maximum specific biogas production $\left(R_{\mathrm{m}}\right)$ (Table 2$)$.

\subsection{Application of the developed biodegradability kinetic (BIK) model for estimation of $k$}

Despite the numerous kinetic models for studying the biodegradability of substrates in literature, simple and easy to apply kinetic models of anaerobic digestions are still scanty. Furthermore, the first order reaction rate constant $(k)$ and maximum biogas yield $\left(y_{\mathrm{m}}\right)$ are two important parameters usually applied for digester sizing and performance evaluation (Linke, 2006). While $y_{m}$ can easily be obtained from simple batch tests, the determination of $\mathrm{k}$ requires very long term experiment in continuous stirred tank reactors (CSTR) (Linke, 2006). This is usually not readily available in literature for many substrates and the few available values are not flexible enough to be applied to any other substrate without experimental investigations (Linke, 2006). The authors have therefore in this study, developed a simple kinetic model for the estimation of $k$ from limited data of short

Table 2

Modified Gompertz model parameters at the different $I / S$ ratios.

\begin{tabular}{llllll}
\hline Digesters & $I / S$ ratio & $\mathrm{A}(\mathrm{L} / \mathrm{g} \mathrm{VS})$ & $R_{\mathrm{m}}$ (L/g VS/day) & $\lambda$ (Days) & $R^{2}$ \\
\hline B-1 & 0.25 & 5.10 & 0.39 & 12.4 & 0.9170 \\
B-2 & 0.5 & 6.30 & 0.39 & 8.5 & 0.9126 \\
B-3 & 1 & 29.58 & 1.26 & 5.0 & 0.9948 \\
B-4 & 2 & 20.77 & 0.76 & 5.6 & 0.9967 \\
B-5 & 4 & 13.9 & 0.41 & 4.6 & 0.9966 \\
\hline
\end{tabular}


Table 3

Parameters for $\mathrm{VS}_{\mathrm{rm}}$ and $k$ determination.

\begin{tabular}{llll}
\hline SRT (Day) & VS removal (\%) & $1 / \mathrm{SRT}\left(\mathrm{Day}^{-1}\right)$ & $\frac{\mathrm{VS}_{\mathrm{r}}}{\mathrm{VS}_{\mathrm{rm}}-\mathrm{VS}_{\mathrm{r}}}$ \\
\hline 80 & $80.7 \pm 4.5$ & 0.0125 & 7.83 \\
62 & $76.5 \pm 2.8$ & 0.0161 & 6.91 \\
41 & $74.3 \pm 3.1$ & 0.024 & 4.45 \\
30 & $78.3 \pm 1.6$ & 0.0333 & 2.54 \\
\hline
\end{tabular}

Table 4

Estimated parameters from the BIK model.

\begin{tabular}{ll}
\hline $\mathrm{VS}_{\mathrm{rm}}(\%)$ & $k\left(\mathrm{~d}^{-1}\right)$ \\
\hline 91.0 & 0.11
\end{tabular}

term experiment using Eq. (17). In accordance with the work of Chen and Hashimoto (1978), Dai et al. (2013), the maximum VS reduction $\left(\mathrm{VS}_{\mathrm{rm}}\right)$ was obtained from the intercept of the linear equation of $\mathrm{VS}_{\mathrm{r}}(\%)$ against $\mathrm{SRT}^{-1}\left(\mathrm{~d}^{-1}\right)$ as $91 \%$ using the obtained data shown in Table 3 . This $\mathrm{VS}_{\mathrm{rm}}$ is similar to documented values in literature for mono and co-digestion of food waste (Dai et al., 2013). The value of $k$ was estimated as $0.11 \mathrm{~d}^{-1}$ using the developed BIK model [Eq. (18)], by plotting $\frac{\mathrm{VS}_{\mathrm{r}}}{\mathrm{VS}_{\mathrm{rm}}-\mathrm{VS}_{\mathrm{r}}}$ against SRT. The slope of the plot represents the value of $k$. Table 4 shows the estimated $k$ and $\mathrm{VS}_{\mathrm{rm}}$ values. Again, it is similar to $k$ values from mono and co-digestion of food wastes in literature (Dai et al., 2013). The BIK model utilized the experimental data of VS reduction over the digestion period to predict $\mathrm{k}$ value. This model can therefore be of great assistance in digester sizing and performance evaluation.

\subsection{Application of the developed maximum biogas production} potential and stability assessment (MBPPSA) model

The developed maximum biogas production potential and stability assessment model (MBPPSA) of Eq. (27) was applied to experimental data to obtain relevant biogas production parameters. Values of maximum biogas production potential $(A)$ obtained for reactors B-1, B-2, B-3, B-4, and B-5 were compared with the maximum biogas production potential $(A)$ values obtained using the popular modified Gompertz model, to serve as a means of model validation.

4.4.1. Estimation of maximum biogas production potential (A) using MBPPSA model

The MBPPSA model can be used for simple estimation of maximum biogas production potential $(A)$ of substrates and for the assessment of process feasibility/stability. The MBPPSA model

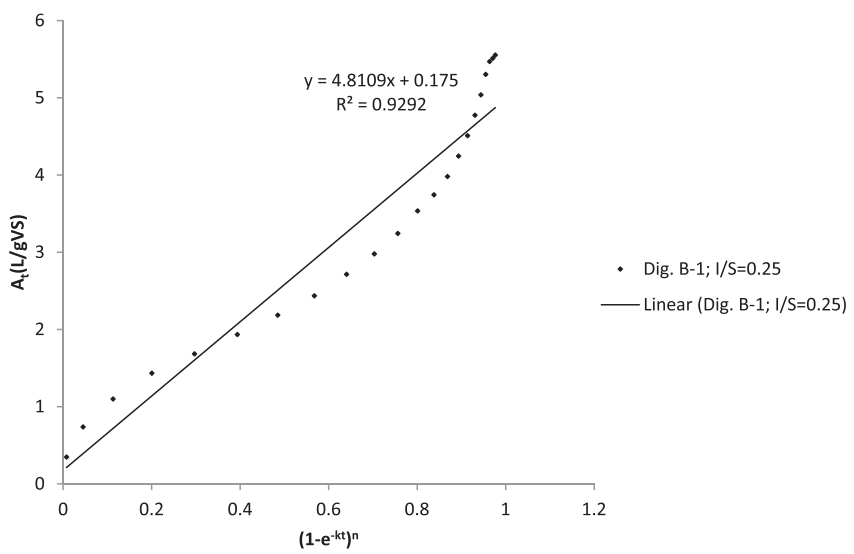

Fig. 4a. Plot of $A_{\mathrm{t}}$ against $\left(1-\mathrm{e}^{-\mathrm{kt}}\right)^{n}$ for digester B-1.

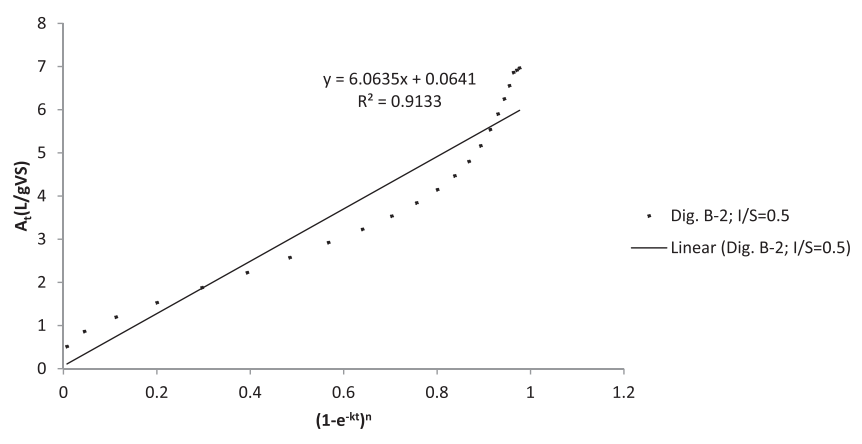

Fig. 4b. Plot of $A_{\mathrm{t}}$ against $\left(1-\mathrm{e}^{-\mathrm{kt}}\right)^{n}$ for digester B-2

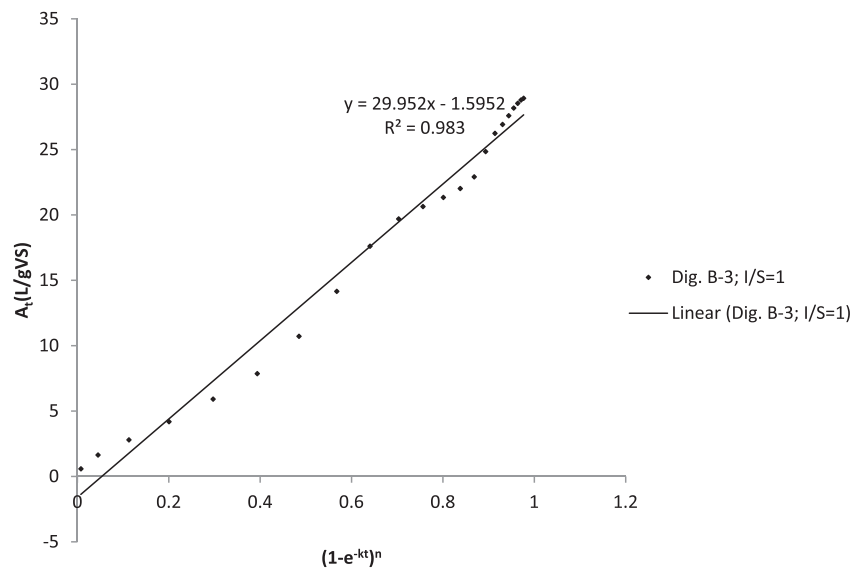

Fig. 4c. Plot of $A_{\mathrm{t}}$ against $\left(1-\mathrm{e}^{-\mathrm{kt}}\right)^{n}$ for digester B-3.

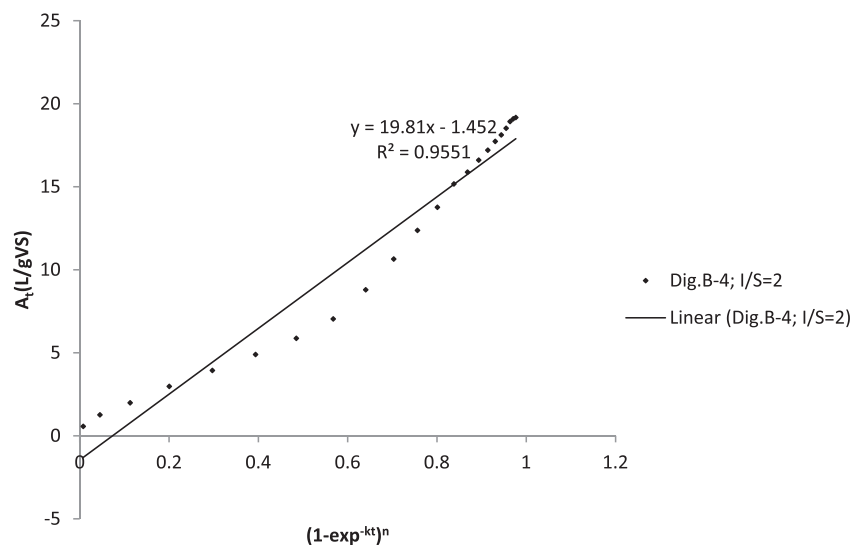

Fig. 4d. Plot of $A_{\mathrm{t}}$ against $\left(1-\mathrm{e}^{-\mathrm{kt}}\right)^{n}$ for digester $\mathrm{B}-4$

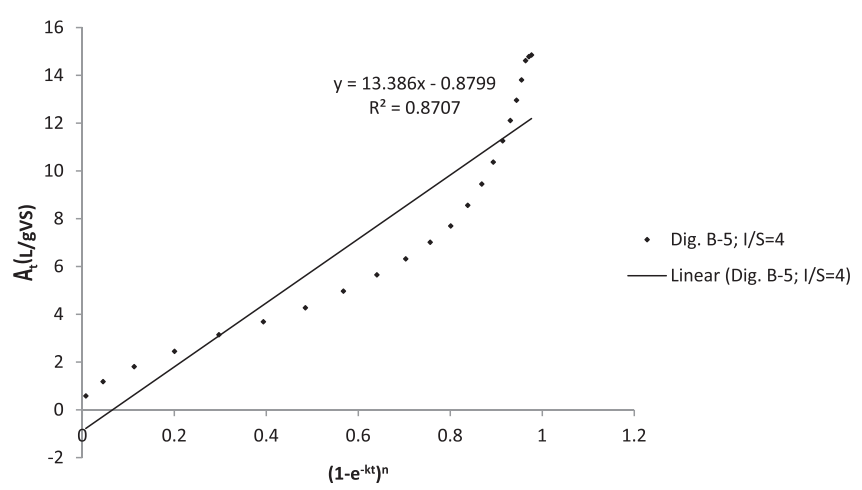

Fig. 4e. Plot of $A_{\mathrm{t}}$ against $\left(1-\mathrm{e}^{-\mathrm{kt}}\right)^{n}$ for digester B-5. 
Table 5

Comparison of the maximum biogas production potential $(A)$ of the MBPPSA model and the modified Gompertz model.

\begin{tabular}{|c|c|c|c|c|c|c|}
\hline Digester & $I / S$ ratio & $\begin{array}{l}\text { A (L/g VS); from modified Gompertz } \\
\text { model; } A_{\mathrm{t}}=A \exp \left\{-\exp \left[\frac{R_{\mathrm{m}} \times e}{A}(\lambda-t)+1\right]\right\}\end{array}$ & $\begin{array}{l}\mathrm{A}(\mathrm{L} / \mathrm{g} \mathrm{VS}) ; \text { from MBPPSA } \\
\text { model } A_{\mathrm{t}}=A\left(1-e^{-\mathrm{kt}}\right)^{\mathrm{n}}+I_{\mathrm{f}}\end{array}$ & $I_{\mathrm{f}}$ & $\begin{array}{l}R^{2}(\text { from MBPPSA } \\
\text { model) }\end{array}$ & $\begin{array}{l}\text { MBPPSA model prediction efficiency } \\
\text { over modified Gompertz model results }\end{array}$ \\
\hline B-1 & 0.25 & 5.1 & 4.8 & 0.9 & 0.929 & $94.1 \%$ \\
\hline B-2 & 0.5 & 6.3 & 6.1 & 0.1 & 0.913 & 96.83 \\
\hline B-3 & 1 & 29.6 & 29.9 & -1.6 & 0.983 & $100 \%$ \\
\hline B-4 & 2 & 20.8 & 19.8 & -1.5 & 0.955 & $95.2 \%$ \\
\hline B-5 & 4 & 13.9 & 13.4 & -0.9 & 0.87 & $96.40 \%$ \\
\hline
\end{tabular}

Table 6

Inhibition/stability check for the digesters based on $I_{\mathrm{f}}$ value.

\begin{tabular}{llcl}
\hline Digester & $I / S$ ratio & $I_{\mathrm{f}}$ value & Stability status $^{\text {B }}$ \\
\hline B-1 & 0.25 & 0.2 & Unstable/inhibited $^{\mathrm{b}}$ \\
B-2 & 0.5 & 0.1 & Unstable/inhibited $^{\mathrm{b}}$ \\
B-3 & 1 & -1.6 & Stable $^{\mathrm{a}}$ \\
B-4 & 2 & -1.5 & Stable $^{\mathrm{a}}$ \\
B-5 & 4 & -0.9 & Stable $^{\mathrm{a}}$ \\
\hline
\end{tabular}

${ }^{a}$ Negative $I_{\mathrm{f}}$ values signify stability.

b Positive $I_{\mathrm{f}}$ values signify inhibition/instability.

was tested and validated, using experimental data from 5 digesters (B-1, B-2, B-3, B-4, and B-5) containing 75\% food waste and $25 \%$ maize husk to give an n-value of 3 for each digester. Figs. 4 shows the respective plots of $A_{\mathrm{t}}$ against $\left(1-e^{-\mathrm{kt}}\right)^{\mathrm{n}}$ for digesters B-1, B-2, B-3, B-4, and B-5 respectively. Results of MBPPSA model parameter $(A)$ obtained for digesters B-1 to B-5, were found to be in good correspondence in both value and trend with the results obtained using the popular modified Gompertz model (Table 5). The MBPPSA model can therefore be used to complement the modified Gompertz model, for anaerobic digestion experiments and feasibility studies. Researchers and other professionals can also use the MBPPSA to do a quick check on results obtained from the popular modified Gompertz model. It is also relatively much easier to determine the parameters of the MBPPSA model, since it can be reduced to just a simple linear equation by plotting $A_{\mathrm{t}}$ against $\left(1-e^{-\mathrm{kt}}\right)^{\mathrm{n}}$ unlike the complex modified Gompertz equation that requires special skill and software for its parameters determination.

\subsubsection{Assessment of digester stability/inhibition status using MBPPSA model}

The MBPPSA model was applied to assess the stability /inhibition status of digesters B-1 to B-5. The intercept of the MBPPSA model $\left(I_{\mathrm{f}}\right)$ was found suitable for digester stability evaluation. A negative value of $\left(I_{\mathrm{f}}\right)$ shows that an anaerobic digestion process is stable. The higher the absolute value of the negative $\left(I_{\mathrm{f}}\right)$, the more stable the digester would be. Positive $\left(I_{\mathrm{f}}\right)$ values indicate inhibition or instability. The higher the positive value of $\left(I_{\mathrm{f}}\right)$, the more unstable/inhibited an anaerobic process would become. Similar stability assessment classification had been used by Yusuf et al. (2011) in their study of biogas production from co-digestion of cow dung and house dung. From Table 6 , it becomes abundantly clear that digesters B-3, B-4, and B-5 with best performance in terms of biogas production potential $(A)$, as expected were found to be stable. However, based on their $\left(I_{\mathrm{f}}\right)$ values, digesters B-3 and B-4 with $\left(I_{\mathrm{f}}\right)$ values of $-(1.6)$ and $-(1.5)$ could be described to be more stable and efficient than digester B-5 with $\left(I_{\mathrm{f}}\right)$ value of $-(0.9)$. In the same vein, digesters B-1 and B-2 were adjudged to be inhibited/unstable as a result of the positive values of their $\left(I_{\mathrm{f}}\right)$ parameter. Furthermore, digester B-1 with $\left(I_{\mathrm{f}}\right)$ value of 0.9 was described as being more inhibited/unstable than digester B-2 with $\left(I_{\mathrm{f}}\right)$ value of 0.1 . The stability assessment result of this model for digesters B-1 to B-5, corroborates very well with the $R_{\mathrm{m}}$ and latency $(\lambda)$ result trend obtained for the digesters using modified Gompertz model as shown in Table 2. From Table 2, digesters B-3, B-4 and $\mathrm{B}-5$, adjudged as stable by the (MBPPSA) model have higher maximum biogas yield $(A)$ and shorter latency $(\lambda)$; while digesters B-1 and $\mathrm{B}-2$ adjudged to be inhibited have comparatively much lower yield and longer $\lambda$. This is clearly an evidence of inhibition/failure for digesters B-1 and B-2. Moreover, the yield of digester B-1 is the least among the other digesters (5.1 L/g VS), yet, it had the longest $(\lambda)$ of 12.4 days. It means that irrespective of the fact that it could not yield reasonable amount of biogas, it also took a comparatively longer period of 12.4 days to start undergoing active methanogenesis. It therefore, sufficiently indicates that digester B-1, going by the result of modified Gompertz model, is more inhibited than digester B-2. This finding corresponds greatly with the values of $\left(I_{\mathrm{f}}\right)$ obtained using the (MBPPSA) model.

The same illustration also goes through for stable digesters $\mathrm{B}-3$, B-4, and B-5. Digester B-3 had the highest potential biogas yield $(A)$ of $29.6 \mathrm{~L} / \mathrm{g} \mathrm{VS}$, the highest maximum specific biogas yield $\left(R_{\mathrm{m}}\right)$ of $1.25 \mathrm{~L} / \mathrm{g} \mathrm{VS} /$ day and the shortest latency $(\lambda)$ of 5 days (Table 2 ). This efficient performance was followed by digesters B-4, before digester B-5. It therefore indicates, that though digesters B-3, B-4, and B-5 are stable, digester B-3 is the most stable and digester $\mathrm{B}-5$ is the least stable. Interestingly, this finding yet again agrees with the values of $\left(I_{\mathrm{f}}\right)$ of (MBPPSA) model, which revealed that though the three digesters were stable, digester B-3 was the most stable $\left(I_{\mathrm{f}}=-1.6\right)$, followed by digester B-4 $\left(I_{\mathrm{f}}=-1.5\right.$, and having B-5 $\left(I_{\mathrm{f}}=-0.9\right)$ as the least stable. The MBPPSA model could therefore be used for feasibility studies and plant design. Both the MBPPSA model and the modified Gompertz model show that $I / S$ ratio of 1 was the best for enhancement of biogas production from the co-digestion of food waste and maize husk. This is in line with the result contained by Boulanger et al.(2012) on the effect of inoculum on biogas production from municipal solid waste. The models also indicated that B-1 and B-2 with lower $I / S$ ratios were inhibited and hence had lower values of maximum biogas production potential (A) and longer latency.

\section{Conclusion}

The biodegradability kinetic (BIK) model developed in this study was found suitable for determination of the first order reaction rate constant $(k)$. The MBPPSA model was used for the estimation of maximum biogas production potential of substrate $(A)$. The results obtained with the MBPPSA model corresponded greatly with the results obtained using the popular but complex modified Gompertz model. Besides, the MBPPSA model was also used to evaluate the stability of anaerobic digesters through its inhibition factor $\left(I_{\mathrm{f}}\right)$, unlike the modified Gompertz model. These models could therefore assist in the design of anaerobic digestion plants.

\section{Appendix A. Supplementary data}

Supplementary data associated with this article can be found, in the online version, at http://dx.doi.org/10.1016/j.biortech.2015.06. 136. 


\section{References}

APHA (2012), American Public Health Association: "Standard Methods for Examination of Water and Waste-water"; 22nd ed., Washington DC, USA.

Boulanger, A., Pinet, E., Bouix, M., Bouchez, T., Mansour, A.A., 2012. Effect of inoculum to substrate ratio $(\mathrm{I} / \mathrm{S})$ on municipal solid waste anaerobic degradation kinetics and potential. Waste Manage. 32, 2258-2265.

Budiyono, Widiasa, I.N., Johari, S., Sunrso, 2010. The kinetic of biogas production rate from cattle manure in batch mode. Int. J. Chem. Biol. Eng. 3 (1), 39-44.

Chen, Y.R., Hashimoto, A.G., 1978. Kinetics of methane fermentation. Biotechnol. Bioeng. Symp. 8, 269-282.

Dai, X., Duan, N., Dong, B., Dai, L., 2013. High-solids anaerobic co-digestion of sewage sludge and food waste in comparison with mono digestions: stability and performance. Waste Manage. 33 (2), 308-316.

Boe, K., Damien, J.B., Jean-Phillippe, S., Irini, A., 2010. State indicators for monitoring the anaerobic digestion process. Water Res. 44, 5973-5980.

El-Mashad, H.M., Zhang, R., 2010. Biogas production from co-digestion of dairy manure and food waste. Bioresour. Technol. 101, 4021-4028.

Ezekoye, V.A., Ezekoye, B.A., Offor, P.O., 2011. Effect of retention time on biogas production from poultry droppings and cassava peels. Nig. J. Biotech. 22, 5359.

FMAWR, 1988. Agricultural policy for Nigeria: strategies for implementation. Federal Ministry of Agriculture, Water Resources and Rural Development, Lagos.

Gerber, M., Span, R., 2008. An analysis of available mathematical models for anaerobic digestion of organic substances for production of biogas. Int. Gas Union Res. Conf., 1-30

Gueguim-Kana, E.B., Oloke, J.K., Lateef, A., Adesiyan, M.O., 2012. Modeling and optimization of biogas production on saw dust and other co-substrates using Artificial Neural Network and Genetic Algorithm. Renewable Energy 46, 276281.

Igal, S., Budiyono, Siswo, S., 2014. Predicting kinetic model of biogas production and biodegradability organic materials: Biogas production from vinasse at variation of COD/N ratio. Bioresour. Technol. 149, 390-397.

Linke, B., 2006. Kinetic study of thermophilic anaerobic digestion of solid wastes from potato processing. Biomass Bioenergy. http://dx.doi.org/10.10.1016/ j.biombioe.2006.02.001.

Li, Y., Zhang, R., He, Y., Zhang, C., Liu, X., Chen, C., 2014. Anaerobic co- digestion of chicken manure and corn stover in batch and continuous stirred tank reactor (CSTR). Bioresour. Technol. 156, 342-347.
Momoh Yusuf, O.L., Anyata, B.U., Saroj, D.P., 2013. Development of simplified anaerobic digestion models (SADM's) for studying anaerobic biodegradability and kinetics of complex biomass. Biochem. Eng. J. 79, 84-93.

Momoh, O.L.Y., Nwaogazie, I.L., 2011. The effect of waste paper on the kinetics of biogas yield from the co-digestion of cow dung and water hyacinth. Biomass Bioenergy 35, 1345-1351.

Moreno-Andrede, I., Buitron, C., 2003. Influence of the initial substrate to microorganisms concentration ratio on the methanogenic inhibition test. Water Sci. Technol. 48, 17-22.

Nathan, C., Pragasen, P., 2012. Biogas prediction and design of a food waste to energy system for the urban environment. Renewable Energy 41, 200-209.

Owamah, H.I., 2014. Biosorptive removal of $\mathrm{Pb}$ (II) and $\mathrm{Cu}$ (II) from wastewate using activated carbon from cassava peels. J. Mater. Cycles Waste Manage. 16, 347-358.

Owamah, H.I., Alfa, M.I., Dahunsi, S.O., 2014a. Optimization of biogas from chicken droppings with Cymbopogon citratus. Renew. Energ. 68, 366-371.

Owamah, H.I., Dahunsi, S.O., Oranusi, U.S., Alfa, M.I., 2014b. Fertilizer and sanitary quality of digestate biofertilizer from the co-digestion of food waste and human excreta. Waste Manage. 34, 747-754.

Owamah, H.I. (2015). Kinetic modeling and optimization study of biogas production from the co-digestion of food waste and maize husk. A PhD thesis submitted to the Department of Civil Engineering, University of Benin, Nigeria.

Owamah, H.I., Izinyon, O.C., 2015. The effect of organic loading rates (OLRs) on the performances of food wastes and maize husks anaerobic co-digestion in continuous mode. Sustain. Energ. Technol. Assessments 11, 71-76.

Raposo, F., Borja, R., Martin, M.A., Martin, A. de la Rubia, M.A., Rincon, B, 2009. Influence of inoculum to substrate ratio on the anaerobic digestion of sunflower oil cake in batch mode: process stability and kinetic evaluation. Chem. Eng. J 149, 70-77.

Tchobanoglous, G., Theisen, H., Vigil, S., 1993. Integrated Solid Waste Management Engineering: Principles and Management Issues. McGraw-Hill U.S, Singapore.

Yusuf, M.O.L., Debora, A., Ogeheneruona, D.E., 2011. Ambient temperature kinetic assessment of biogas production from co-digestion of horse and cow dung. Res. Agric. Eng. 57 (3), 97-104.

Zhang, R., El-Mashad, H.M., Hartman, K., Wang, F., Liu, G., Choate, C., Gamble, P., 2006. Characterization of food waste as feedstock for anaerobic digestion. Bioresour. Technol. 98, 929-935.

Zhu, J., Yi, Z., Fuqing, X., Yebo, L., 2014. Solid-state anaerobic co-digestion of hay and soybean processing waste for biogas production. Bioresour. Technol. 154, 240 247. 